\title{
artículos
}

\section{El Cuadro de Ánimas de la parroquia de Santiago, de Málaga}

\author{
José Domínguez Cubero \\ Real Academia de Bellas Artes de Granada
}

\section{RESUMEN}

El "Cuadro de Ánimas" de la parroquia de Santiago de Málaga, pintado hacia 1665 por el discípulo de Alonso Cano, Juan Niño de Guevara, evidencia la verdad de la Comunión de los Santos, una idea quizá propuesta por el mismo autor, en base a su sólida formación cristiana. Hay, pues, clara alusión a los tres grupos o iglesias que integran el dogma. La Militante la ejemplifica el catafalco de los oficios de difuntos, significando los sufragios que elevan los fieles en su favor. La Purgante está presente en las ánimas sufrientes que purgan sus cultas en el fuego purificador. Por fin, la Triunfante va indicada en el santoral que preside: Santiago, el titular de la parroquia, derramando sobre los penados la gracia de salvífica, ante la presencia de la Virgen María con el Niño en brazos, y dispuesto sobre un orbe, cual símbolo del Creador, y con la cruz de la Redención mostrada en la mano; una idea que insistentemente está reiterada en esa otra cruz que corona el catafalco y centra la composición, como una concreción del cristocentrismo tridentino.

PALABRAS CLAVE: Pintura Barroca/ Ánimas del Purgatorio/ Iconografía/ Juan Niño De Guevara/ Málaga.

\section{Animas box in the Parish Church of Santiago in Málaga}

ABSTRACT

Animas box in the parish of Santiago de Málaga, painted around 1665 by a pupil of Alonso Cano, Juan Niño de Guevara, shows a message based on the Communion of Saints, perhaps devised by the author based on their solid Christian formation. Logically, the issue is a clear allusion to the three groups that make up this concept: the Church Militant, exemplifies the bier of the deceased offices meaning the votes that raise the faithful to honor their dead, the Church Suffering, is present in the souls suffering in the fire purging his sins, and the Church Triumphant, indicated by the saints means the holder of the parish prisoners pouring on the grace of salvation, the divine presence of the Virgin Mary and Child Jesus depicted as Creator and Redeemer of the world. Concept, the latter, strongly reiterated that cross the entire composition that focuses on burial mound, as a specific example of Christ-Trent.

KEY WORDS: Baroque painting/ Animas of Purgatory/Iconography/Juan Niño De Guevara/ Málaga.

\section{INTRODUCCIÓN.}

Atraído por los comentarios a la buena calidad que afloraba en el "Cuadro de Ánimas" (200 cm. X 299 cm.; óleo sobre lienzo) de la parroquia de Santiago, de Málaga, al compás que avanzaba el proceso de su restauración, por parte de los licenciados Francisco Fuentes del Olmo y Francisco de Paula Ruano Garrido, y ante

* DOMÍNGUEZ CUBERO, José: "El Cuadro de Ánimas de la parroquia de Santiago, de Málaga”, en Boletín de Arte $\mathrm{n}^{\circ}$ 32-33, Departamento de Historia del Arte, Universidad de Málaga, 2011-2012, págs. 223-232. Fecha de recepción: Junio de 2011 


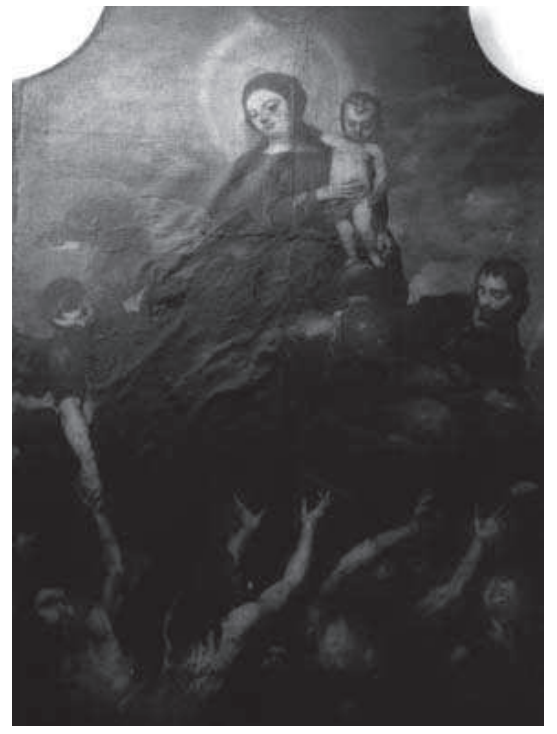

1. Vista general antes del cuadro antes de la restauración. (Foto. F. Fuentes).

la insistencia de los mismo, me personé en el improvisado taller, instalado en una dependencia del templo, no sólo con el interés de comprobar la calidad de tan celebrada obra, sino también con el deseo de adentrarme en los secretos del arte pictórico generado en el barroco malagueño, tan genuino pese a su inserción en el granadino, como ocurre igualmente en la escultura.

Efectivamente, lo que lucía limpio de los desajustados repintes de anteriores intervenciones ${ }^{1}$, aún con el aparejo de pasta cubriendo grietas y lagunas, nos mostraba una pieza principal de muy cuidado dibujo y delicadas tonalidades, conformando una composición en orden cerrado y rigor simétrico, un tanto impropia para el momento de la segunda mitad del Seiscientos en que se realizó, justo cuando prevalecía la exuberancia, las agilidades corpóreas, las fugas perdidas en el infinito de rompimientos celestes...

Y es precisamente este cariz de tradición racionalista, tan ajustado a los modelos del barroco granadino que propugnara Alonso Cano, lo que hace que la obra se puede considerar plenamente adscrita a esta escuela granadina. Pero si todo esto es fundamental para llegar a su conocimiento, a su catalogación, etc, la completa exégesis se realiza tras una meditada lectura del mensaje ideológico que desprende, donde, con claridad meridiana, se nos manifiesta la conceptuación teológica de la Comunión de los Santos, muy ponderada por la doctrina tridentina.

\section{COMPOSICIÓN ICONOGRÁFICA.}

Tan perfecta organización, insistimos, rigurosamente simétrica y centralizada, viene a inscribirse en un espacio piramidal, en cuya cúspide se ubica la Virgen María, sentada, con Cristo Niño en pie sobre su regazo, desnudo, y como Creador y Redentor

1 En la parte posterior, se anotan dos restauraciones hechas en tiempos conflictivos de la Historia de España, la primera en octubre, 18 de 1868, por Ángel Romero; la segunda, también en Octubre, 18 de 1931, por Celestino Corceles. 


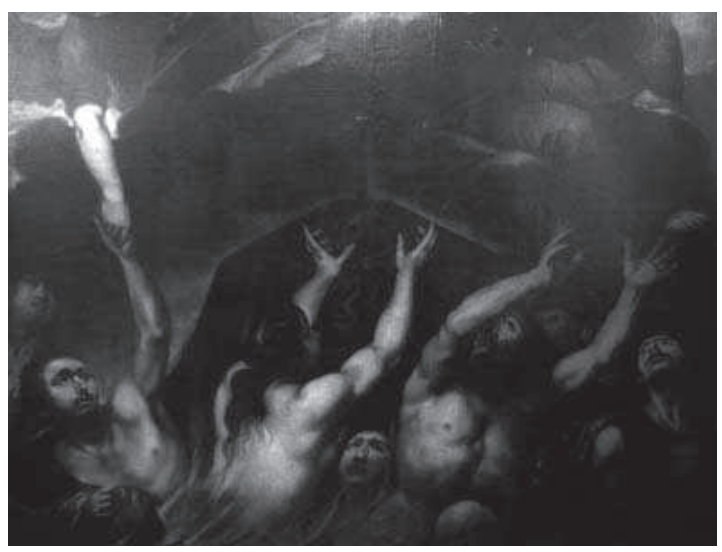

del mundo, bien significado en la esfera u orbe que le sirve de escabel y en la cruz que porta en su mano derecha. La Madre, cual Theotocos, lo muestra, ataviada con los alegóricos tonos bíblicos, rojo jacinto en la túnica, y en el manto el inmaculista azul, entronizada sobre densas nubes, nimbado de luz blanca su hermoso rostro, y ante un celaje vaporoso de muy suave y delicada atmósfera celeste. En los extremos, a la derecha, como suele ser corriente en estos cuadros, aparece el Santo titular de la parroquia, Santiago, con traje de peregrino, con su esclavina portando la cruz santiaguista y la venera romera para mayor identificación, todo envuelto entre nubes, jerarquizado en escala inferior a la suprema deidad, y derramando el agua contenida en una jarra metálica, cual gracia salvadora, sobre los penados. Al lado opuesto, contrarrestando la composición, un ángel asoma extendiendo su mano a la salvación de las ánimas justificadas de la franca baja.

Los protagonistas sobrenaturales, con serena y mayestática presencia, van incitando con sus miradas a que el espectador tienda a la contemplación de la realidad que allí se vive. Clara invitación que no tiene más sentido que incitar al fiel al adoctrinamiento por medio de la meditación sobre la salvación del justo, que en realidad es el fin doctrinal propuesto.

El recurso de separar lo sobrenatural, en las alturas, de lo natural o terrenal, en el plano bajo, fue usado desde tiempos medievales tomando auge en la Italia de Quattrocento. Lo usaron los pintores de Padua. AAndrea Mantenga, desde luego, le vino bien para diferenciar dos espacios en su Oración en el Huerto. Después se generaliza, y lo hace Rafael en su famosa Disputa del Santísimo Sacramento, de la Stanza della de Segnatura; en la Madonna de Foligno, de la Pinacoteca Vaticana; o en el retablo de Santa Cecilia, de la Pinacoteca Comunale de Bolonia. Cuadros que tanta evocan la organización del de nuestro interés. El recurso, desde luego, es de fortuna en España. El Greco lo usó con éxito, no olvidemos el Entierro del Conde de Orgaz. Después lo 


\begin{tabular}{|c|c|}
\hline 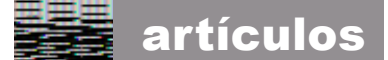 & José Dominguez Cubero \\
\hline
\end{tabular}

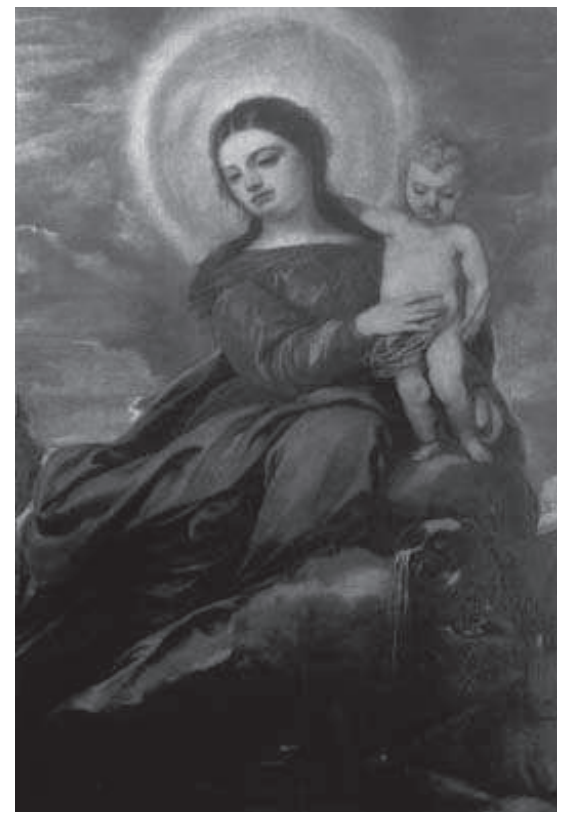

3. La Virgen con el Niño (Foto. F. Fuentes).

prosigue el Barroco, bástenos al caso, en la misma Málaga, el hermoso lienzo de la Virgen del Rosario de la Catedral que pintara Alonso Cano, y que tanta similitud compositiva guarda con el que nos entretiene.

Atendamos ahora al plano inferior. Lo primero que percibimos es la disposición de los personajes en orden a unas diagonales que inciden en un punto rigurosamente situado en la mitad del lienzo, sobre el eje axial, donde aparece la cruz que corona el túmulo funerario, un elemento oscuro, envuelto en el ambiente tenebroso que rellena casi al completo la zona media sirviendo de pantalla a las figuras delanteras para mayor distinción de su protagonismo. Se trata de una pieza, en lugar interregno, cubierta de ricos paños fúnebres, con recamados en oro, destacando el símbolo mortuorio de la calavera sobre tibias cruzadas, dispuesto bajo la cruz y en unidad conceptual con ella, cual símbolo del Calvario, donde se forjó el misterio cristiano de la Redención.

Y ya, en los espacios inferior, la escenificación del Purgatorio, usando de un alarde magistral en dibujo y color, bien candente en los vigorosos y bien constituidos cuerpos desnudos, aún con notados desajustes, desequilibrados en sus movimientos individuales, con brazos danzantes dirigidos muy inteligentemente hacia esas líneas perspectivas, que nos conducen a la cruz redentora, tal y como lo viene a indicar la robusta dama de ademán suplicante, que centraliza la escena, o el interesantísimo cuerpo varonil, de bello escorzo y forzado gesto, que asoma entre penumbras. Hay penados que se asen a los filos del paño fúnebre y otros que intentan refugiarse bajo él, siempre como medio expresivo de la esperanza salvadora que su presencia representa; mientras otros, plácidamente, se sienten consolados por el beneficio propiciado desde las alturas. Es precisamente en este apartado donde los estilemas barrocos de movimiento y distorsión se apartan de la tónica clásica que domina lo restante. 


\section{Aspectos iconológicos.}

La creencia en la inmortalidad del alma es consustancial a la existencia de la humanidad sin distinción de tiempos y culturas. Todas las civilizaciones han creído en el más allá y han invocado a los espíritus estableciendo una intercomunicación que haga efectiva la acción intercesora de las oraciones y las buenas obras como envíos de ofrendas o sufragios. Los descubrimientos arqueológicos constantemente ponen de manifiesto esta norma escatología. Y el arte, que no es más que la manifestación de la humanidad, nos ofrece al respecto sobrada elocuencia desde las primeras civilizaciones. Al respecto, ahí tenemos las expresiones plásticas egipcias representando el Juicio de los Muertos ante las divinidades de Anubis, Thot y Osiris.

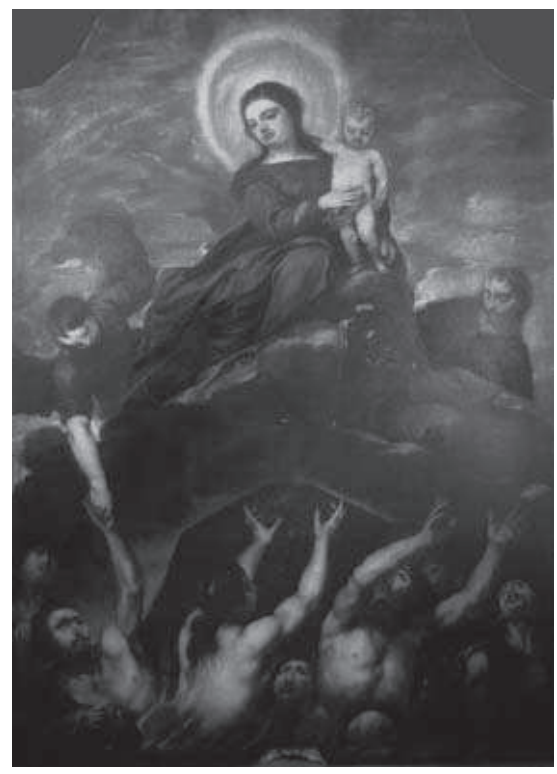

4. Vista general del cuadro (Foto. F. Fuentes).

Hemos, pues, de admitir el sentido continuista que el pensamiento cristiano tiene en este aspecto. Un pensamiento que, plásticamente, no se expresó del mismo modo. En tiempos renacentistas, son raros los cuadros de ánimas. Prolifera, sin embargo, la visualización del alma justificada, representada con anatomía infantil, a veces, un tanto amorfa $^{2}$, izada o asunta directamente por ángeles, en ocasiones sobre telajes que portan puttis a veces implicados con otras figuraciones míticas, fantásticas, puras alegorías de virtudes, extraídas de los repertorios grecorromanos, puestas en pinturas o grabados sobre sepulcros y capillas funerarias, lugares donde siempre encuentra cabida alguna escena pasionista ejemplificando la acción redentora de Cristo, único fundamento teológico para la glorificación de las almas según los principios cristianos de las postrimerías.

Frente al pensamiento protestante, el Concilio de Trento (1545-1563) abrió nuevas posibilidades al tema. Un tema que de inmediato va a entrar en el quehacer artístico al quedar fehacientemente definidas varias consideraciones doctrinales,

2 Es el caso, entre otros, que encontramos en el sepulcro del camarero don Francisco Vago en San Pablo de Úbeda (Jaén) (DOMíNGUEZ CUBERO, J., De la Tradición al Clasicismo Pretridentino en la Escultura Giennense, Jaén, 1995, pp. 129,130), y el más conocido, en el famoso cuadro de El Entierro del Conde de Orgaz del Greco. 
como el valor de las indulgencias, el de los méritos de las buenas obras, la eficacia de las oraciones y sufragios, y sobre todo, el hecho de fijar la realidad de la existencias del Purgatorio ${ }^{3}$, una verdad que ya fuera definida como tal en asambleas eclesiales anteriores, tras un largo proceso debatido desde finales del siglo XII, al decir del estudio de Jacques Le Goff ${ }^{4}$. Lógico es, por lo tanto, que sea en los tiempos posconciliares cuando proliferen las cofradías y hermandades de ánimas y, como consecuencia, la infinidad de cuadros que las representan; rara era la parroquia, iglesia conventual e incluso ermita que no contara con un ejemplar.

Generalmente, son obras que se ajustaban, más o menos, a un arquetipo que viene a mostrar en el nivel bajo el espacio de los condenados purificando sus culpas con el fuego temporal, aunque no es raro encontrar modelos representando también el eterno fuego infernal, ubicado en el subsuelo del Purgatorio, como ordenación de estratos clasificados en proporción directa con la pena y maldad del condenado, a mayor culpa mayor profundidad. Es este el espacio del dominio del terror, donde dominan los pululantes demonios, monstruos, sierpes, etc. Distinta es la visión del Purgatorio, con unos condenados que mitigan la pena con la virtud de la espera, a veces el estado anímico viene indicado con la representación alegórica de la Melancolía, caso de ciertos ejemplares en la ciudad de Jaén, dos, dieciochescos, uno, en pintura, de regular factura, colgado en la parroquia de Santa María Magdalena, anónimo, pero vinculable al pintor Pancorbo, y otro, de talla, sobresaliente en factura, con seguridad debido al malagueño afincado en Jaén, José de Medina y Anaya, donde bien pudiera estar incluido su retrato, ya muy acertadamente comentado por Emilio Lara ${ }^{5}$. En ambos entre los penados aparece la figura alegórica de la melancolía, meditativa, con la cabeza apoyada en el brazo, pura traducción de la tristeza del alma por el alejamiento temporal de la contemplación divina. Más diversidad existe en la representación de la Gloria. Aquí, bajo la presencia de la divinidad, donde es corriente encontrarse la figuración de la Santísima Trinidad, a veces con Cristo portando la cruz redentora, y casi siempre acompañado de la Virgen María, reivindicando su colaboración en el misterio redentor, y la presencia de un cortejo de bienaventurados contemplando el trasiego ascensional de las almas santificadas, guiadas por ángeles a la eterna felicidad de visión divina, muchas veces ante la atenta mirada del santo protector del templo parroquial o monástico, sírvanos de ejemplo de lo último el que se halla en el Santuario de la Victoria ${ }^{6}$ de la misma Málaga. Y esto, sin olvidar, en ocasiones, la representación del Juicio de las Almas, como un remedo que sacralizara en los principios cristianos las

3 CONCILIO DE TRENTO, II ED. Intra Tex. C.T., Eúlogos, 2001. “ ... hay Purgatorio; y que las almas detenidas en el reciben alivio con los sufragios de los fieles...".

4 LE GOFF, J., El nacimiento del Purgatorio ,Madrid, 1981, pp. 154-157.

5 Sobre este tema podemos consultar a LARA LÓPEZ, Emilio, "El retablo de Ánimas de la Iglesia de San Ildefonso de Jaén. Una iconografía melancólica", Senda de los Huertos, números 51, 52, 1998, pp. 23 y 29; "La Melancolía", Historia, 16, n 310, febrero, 2002, pp. 99-113.

6 Aunque se ha pensado en Niño de Guevara como autor del lienzo (CLAVIJO GARCíA, A., Juan Niño de Guevara, pintor malagueño del siglo XVI. Universidad de Málaga, 1998. pp. 134-135), le cabe mejor acoplo en la obra del dieciochesco Diego de la Cerda. 
deidades egipcias, de manera que la función de Anubis es practicada por el príncipe arcangelical, San Miguel, y las del supremo Osiris, por la justicia misericordiosa de Dios, representado unas veces por la Trinidad, otras por Cristo, o por María con su divino Niño, esto último viene impulsado por ciertas órdenes religiosas, sobre todo, la de carmelitas y dominicos, que respectivamente hacen presidir sus cuadros de ánimas con las advocaciones marianas del Carmen y del Rosario, respectivamente.

Mensaje ideológico del cuadro de Ánimas de Santiago.

Pues bien, sentadas estas premisas creemos estar en condiciones de pasar a descifrar el mensaje iconológico que encierra nuestro lienzo. Esencialmente, la representación, tal y como se indicó, no es más que una metáfora de la Comunión de los Santos; o sea, la intercomunicación existente entre todos los fieles de la Iglesia, ya estén gozando de la contemplación divina, llenos de gracia santificante, constituyendo la Iglesia Triunfante; o bien purificando sus culpas, integrando la llamada Iglesia Purgante; o por último practicando aún en la Tierra, en esa Iglesia Militante.

Una simple mirada es suficiente para identificar esta triple parcelación, que aquí se organiza en movimiento circular, de dentro hacia fuera. $Y$ así encontramos en la zona intermedia los favores que la Iglesia Militante, con sus oraciones, sacrificios, y dádivas, alcanza para mitigación y remedio de los penados, tan candentemente representado en el catafalco o capelardente que levantan las iglesias en las solemnes misas u oficios de difuntos, coronado por el aludido Calvario ubicado, como sabemos, en el centro del conjunto, tal y como corresponde a tan supremo protagonismo en la acción redentora y salvadora de Jesús.

A las gracias conseguidas por medio de los fieles vienen a sumarse las alcanzadas por los suplicantes bienaventurados, triunfantes ya en la Gloria, que serán revertidas a los purgantes para mitigación de penas y depuración de las manchas de culpabilidad, todo tan signado en el cuadro por medio de la ajustada figura del agua apagando el fuego que Santiago, como símbolo parroquial, arroja con la mencionada vasija, puro símil, muy usado en el Barroco, para significar la gracia divina purificadora y redentora de las ánimas ${ }^{7}$, que en este caso se aplica a las impolutas, seráficas y santas, a la manera que se hace en otros cuadros de nuestro Siglo de Oro, para significar la pureza de las santas almas, destacando sobre manera los de San Francisco de Asís, uno pintado por Valdés Leal, hacia 1665, conservado en el Museo de Bellas de Sevilla, y otro de similar cronología dejado por el giennense Sebastián Martínez en el monasterio cordobés de Santa María de Gracia. De todas formas, el modelo no es original, que debió plagiarse de ciertos grabados circulantes.

7 Véase al respecto GÁLLEGO, J., Visión y símbolos en la pintura española del Siglo de Oro. Madrid, 1984, p. 202. 
Una estampa barroca de la misma época muestra al Papa San Gregorio pidiendo a Jesús y María con sus famosas "Misas de gregorianas" la concesión de la gracia santificante, que igualmente es derramada, bajo el símbolo del agua contenida en un ánfora, por un ángel, mientras los penados la reciben con ansiedad disponiendo los brazos implorantes, todo muy paralelos con los de la pintura que comentamos ${ }^{8}$.

Conviene indicar también que nuestro lienzo tiene, pues, mucha connotación localista, como pensado para adoctrinar a la feligresía, dando más importancia a la misericordia divina, representada en el sereno grupo de María y el Niño, que a la presencia del Dios justiciero de tiempo medieval. De ahí, la mansedumbre reinante en el Purgatorio, un lugar que aquí aparece desprovisto de todo cuanto pudiera significar pavor y violencia, con los penados más pendientes del sufrimiento de sentido que de daño, sólo indicados por las leves llamas en torno a unos cuerpos de rostros jóvenes, serenos y plenos de una piedad que clama la gracia favorecedora de la oración pía del feligrés santiaguista.

Con esto, bien puede quedar manifiesto que el ideólogo de la representación no debió estar muy alejado de la acción parroquial, y, desde luego, nos deja bien candente su amplia formación en la teológica contrarreformista de las postrimerías.

\section{Autoría y Valoración artística.}

Es un hecho admitido por la escasa crítica que hasta ahora se le ha acercado que la autoría corresponde a Juan Niño de Guevara (1632-1698). Un pintor nacido en Madrid, pero muy pronto avecindado en Málaga, por lo que con propiedad se le puede considerar hijo de la tierra. El pintor Antonio Palomino(1655-1726) ${ }^{9}$ trazó sus primeros perfiles biográficos y de formación, después repetidos por Ceán Bermúde $z^{10}$ y otros ${ }^{11}$, y recientemente clarificados por el malogrado historiador Agustín Clavijo ${ }^{12}$, que verificó datos en una acción archivística francamente ardua.

Se formó bajo el mecenazgo de don Antonio Enríquez de Porres, obispo por dos veces de Málaga (1634-1638) y (1641-1645), posible pariente por línea materna, a quien

8 MARTÍNEZ CARRETERO, Ismael, “La devoción del rosario y el santo escapulario del Carmen”, en Rosarium Virginis Mariae, Catálogo Exposición, 2003, p. 134.

9 PALOMINO DE CASTRO Y VELASCO, Antonio, A.; El Museo Pictórico y Escala Óptica. Madrid, 1947, pp. 1074-1077.

10 CEÁN BERMÚDEZ, Juan A. Diccionario de los más ilustres profesores de las Bellas Artes de España. Tomo III, p. 232.

11 Los datos biográficos y profesionales se completan también con los trabajos de LLORDEN, A, Pintores y doradores malagueños, Ávila, 1959, y WETHEY, Harold E.,"Juan Niño de Guevara", Academia. Madrid, 2 , 1953, pp. 137-142.

12 CLAVIJO GARCÍA, Agustín, "Juan Niño de Guevara y su obra en la Catedral de Málaga", En XXIII Congreso Internacional de Historia del Arte entre el Mediterráneo y el Atlántico. Granada, 1973. Universidad. Departamento de Historia del Arte. Granada, 1978, pp. 57-66. - "Un pintor del siglo XVII. Juan Niño de Guevara", en Revista Jábega, n 5, 1974, pp. 75-82. - Juan Niño de Guevara, pintor malagueño del siglo XVII. Universidad de Málaga, 1998. 
sirvió su familia. Adquirió una esmerada instrucción en letras y religión, y, en cuanto a la profesión, parece que muy temprano entró en el taller malagueño del pintor hispanoflamenco Miguel Manrique, seguidor de Rubens, aunque por poco tiempo, sólo en los tres o cuatro años que a Manrique le quedaban de vida. Después pasó a Madrid, rematando aprendizaje con Alonso Cano, con quien parece que mantuvo contacto el resto de su existencia, ya transcurrida por entero en Málaga, morando en la colación de Santiago.

De todas formas, la crítica le ha resaltado un estilo con definición ecléctica, donde entran como factores concluyentes dos principios: lo canesco, y un regusto barroquista flamenco. Lo primero pudo ser en tal grado que nos hace considerar si, además de los "dibujos y diseños para sus cuadros" ${ }^{\prime 13}$ que el mismo Cano le proporcionaba, hubo una directa asesoría en alguna de las ocasiones en que el célebre artista visitó la ciudad, tal vez cuando anduvo pintando en 1665 para el obispo Fray Alonso de Santo Tomás el referido cuadro de la Virgen del Rosario. Si esto pudo ser así, no sería descabellado admitir la participación o colaboración del célebre maestro en nuestro cuadro. Son demasiadas las concomitancias entre las Ánimas y la Virgen del Rosario, no sólo las formalista, sino también las de técnicas, como la aplicación de pinceladas, la paridad de manchas cromáticas, y los recursos efectistas de luz y sombras provocando relieve, una observación muy candente en la imagen de María, sobre todo en su rostro, que se aparta de todos cuantos pintó Niño de Guevara representando a la Madre de Dios. Efectivamente, la zona alta guarda extrema fidelidad con la figura de la Virgen del Rosario, aunque la pose se desvíe levemente para adoptar, sobre todo, el Niño, mejor ajuste a un dibujo de la Virgen y el Niño entre ángeles, que hiciera el propio Cano, guardado en los fondos del Museo del Prado ${ }^{14}$. Por otro lado, la tipología de los restantes personajes también responden a la impronta canesca, que es la que adopta nuestro pintor en las obras de su segunda etapa (1653-1680), la de mayor acercamiento a lo granadino; para asegurarlo, bástenos contemplar las obras que guarda la Catedral de Niño de Guevara. Así, por ejemplo, el apóstol Santiago y el ángel, que flanquean el grupo central van evocando otras pinturas suya documentadas, como, el San José de la Huída a Egipto, del Santuario de San José, o el Arcángel San Miguel de la Catedral, muy candentemente en el trato anatómico de las extremidades superiores. Todo dentro de un naturalismo claramente perfilado que igualmente encuentra vinculación con pinturas de José Ribera, "El Españoleto", lo que ya percibió Clavijo ${ }^{15}$. El detalle se concreta en nuestro lienzo en el vahído tenebrismo de la zona baja, y en la relación existente entre el escorzo del varón que levanta los brazos ocultando parte de su extático rostro y los profetas Ageo y Daniel que dejara Ribera en los murales de la cartuja de San Marino de Nápoles, lo cual nada tiene de extraño dada la circulación de estampas y las concomitancias con obras del propio Cano ${ }^{16}$.

13 Así comenta Clavijo (op. cit. nota 37) de un dato entrecomillado proporcionado por GÓMEZ- MORENO, M La pintura en Granada (manuscrito inédito), Biblioteca del Museo Provincial de Bellas Artes, Granada, 1899, p. 53.

14 Publicado por Sánchez Cantón en Dibujos españoles, t. IV, n 312

15 CLAVIJO, op. cit. pp. 63-64.

16 NAVARRETE PRIETO, B. y SALORT PONS, S., "El saber de un artista: fuentes formales y literarias en la obra de Alonso Cano", Alonso Cano, espiritualidad y modernidad artística. Granada 2001-2002, p. 140. PÉREZ SÁNCHEZ, A. E. "Ribera y España". Ribera. Madrid, Museo Nacional del Prado, p. 91. 
En cuanto al barroquismo flamenco que le pudo llegar vía Manrique, como sabemos, es algo también admisible en esta obra. Efectivamente, si en la base de la composición y elección cromática subyace el impacto del pintor granadino, ciertos gestos corporales en los personajes del Purgatorio se apartan un tanto de las serenidades inherentes a esta pintura para incardinarse en modelos de movilidad barroquizante, pero siempre haciendo uso de prestaciones pretéritas ensayadas ya en el propio renacimiento italiano, como puede ser la robusta dama que de espaldas clama con los brazos levantados, remedo evidente de la figura que aparece en el plano inferior del fresco que dejó Rafael en 1514 en la Stanza dell'Incendio: Incendio del Borgo, en el palacio del Vaticano. De todas formas, no faltaban fuentes inspiradoras. La pintura flamenca ofrecía amplia cantera, incluso en nuestra propia tierra; en este sentido, había que tener presente el cuadro del Juicio Final que pintó Martín de Vos (Amberes, 15321604) para el retablo del convento de San Agustín, en Sevilla, hoy guardado en el Museo de Bellas Artes de esta ciudad, presentando una hermosa pintura donde se representa un amplio campo de resucitados un tanto danzantes, envueltos en claros y vaporosos cromatismos, ofertando un interesante modelo al interés de esta temática.

El protagonismo, total o compartido, que corresponde a nuestro pintor en el aspecto práctico, también le puede caber en el teórico, como creador o mentor de la ideología desarrollada. No olvidemos dos puntos claves que favorecen la sentencia; uno, su condición de feligrés en la parroquia de Santiago; y otro, la profunda formación que poseyó en doctrina cristiana, de lo que dejó testimonio practicando la caridad sin límite, tanto que le llevó casi a abordar la muerte en la peste de $1649^{17}$. Por otro lado, cuenta bastante el saber que fue miembro integrante de Escuela de Cristo, institución que se extendió mucho por la diócesis malacitana, cuya misión prioritaria era colaborar con los clérigos, cual misionero seglar, en la predicación cristiana ${ }^{18}$. Labor que, lógicamente, exigía, además de elocuencia y ejemplo de vida, un vasto conocimiento doctrinal, basado en textos bíblicos canónicos o no canónicos. Esto último lo demuestra igualmente su pintura. El bello cuadro del Reposo en la Huida a Egipto, ya indicado, no es más que una alusión al tema apócrifo de la caída de los ídolos de Sotina ${ }^{19}$, que aparecen rotos por el suelo en medio de la monumental y bien constituida arquitectura del templo. $Y$ es que, pese a la ortodoxia defendida en estos momentos contrarreformistas, lo apócrifo sigue conviviendo con lo canónico.

Considerando lo expuesto, no nos puede extrañar que el maestro viera en la pintura un vehículo de expresión sensible para el adoctrinamiento de los fieles en las verdades del dogma, como un recurso más en su ministerio catequético. Así debió entenderlo el profesor Clavijo cuando define su arte "como fiel reflejo de su propia vivencia "20.

17 CLAVIJO, op. cit. p. 22. Se refiere a los cuidados que prestó a los apestados de Málaga en la epidemia de 1649 , de la que se infectó quedando posteriormente sano.

18 Idem, p. 22.

19 Pseudo Mateo, XXIII.

20 CLAVIJO, op. 